\title{
Susceptibility testing of Atopobium vaginae for dequalinium chloride
}

\author{
Guido Lopes dos Santos Santiago ${ }^{1 *}$, Philipp Grob², Hans Verstraelen ${ }^{3}$, Florian Waser ${ }^{2}$ and Mario Vaneechoutte
}

\begin{abstract}
Background: Atopobium vaginae and Gardnerella vaginalis are major markers for bacterial vaginosis. We aimed to determine the MIC and MBC range of the broad-spectrum anti-infective and antiseptic dequalinium chloride for 28 strains, belonging to 4 species of the genus Atopobium, i.e. A. vaginae, A. minutum, A. rimae and A. parvulum.

Methods: The MIC was determined with a broth microdilution assay.

Results: The MIC and MBC for Atopobium spp. for dequalinium chloride ranged between $<0.0625$ and $2 \mu \mathrm{g} / \mathrm{ml}$.

Conclusions: This study demonstrated that dequalinium chloride inhibits and kills clinical isolates of $A$. vaginae at concentrations similar to those of clindamycin and lower than those of metronidazole.
\end{abstract}

\section{Background}

Bacterial vaginosis (BV) is a polymicrobial condition whereby the lactobacilli dominated vaginal microflora is overgrown by anaerobes [1], such as Gardnerella vaginalis and Atopobium vaginae [2]. BV is the most common cause of vaginal complaints among women of childbearing age [3].

At the moment there are two recommended therapies for BV, oral metronidazole or vaginal clindamycin [4], both with one-month cure rates of $60-90 \%[5,6]$. The recurrence rate is high, about $30-50 \%$ of the women have a relapse within 2-3 months and 50-70\% within 6 to 12 months $[3,5,6]$. Moreover, resistance of BV-associated anaerobic bacteria to metronidazole (1\%) versus $17 \%$ clindamycin resistance at baseline, and 53\% clindamycin resistance after therapy has been reported [7]. In particular, it has been shown that $A$. vaginae can be metronidazole resistant [8-10].

Because both clinical and microbiological efficacy of the current antibiotic treatment of BV with metronidazole, other 5-nitro-imidazoles and clindamycin are not completely satisfactory, with a high recurrence rate of vaginosis [3,5-9], alternative treatments, such as the topical application of broad spectrum anti-infectives and

\footnotetext{
* Correspondence: guido.lopesdossantossantiago@ugent.be 'Laboratory Bacteriology Research, Faculty Medicine \& Health Sciences, University of Ghent, De Pintelaan 185, Ghent 9000, Belgium Full list of author information is available at the end of the article
}

antiseptics, could offer a solution to bypass possible antibiotic resistance.

One such antiseptic is dequalinium chloride, for which the broad microbicidal activity against aerobic and anaerobic bacteria as well as yeasts has been demonstrated previously [11], and for which clinical efficacy and safety in the treatment of BV and other vaginal infections has been shown [12-14].

The aim of this study was to determine the Minimal Inhibition Concentration (MIC) and Minimal Bactericidal Concentration (MBC) of DQC for strains of the genus Atopobium.

\section{Methods}

\section{Bacterial strains}

Three strains of $A$. vaginae (CCUG 44258, CCUG 44125 and CCUG $38953^{\mathrm{T}}$ ) and one strain each of $A$. minutum (CCUG 31167), A. rimae (CCUG 31168) and A. parvulum (CCUG 32760) were obtained from the Culture Collection of the University of Göteborg, Sweden (CCUG). All other strains were clinical vaginal isolates obtained during studies between 2003 and 2010 (Table 1), and isolated after anaerobic culture (at $37^{\circ} \mathrm{C}$ for minimum 3 days) on Colombia agar (Becton Dickinson (BD), Erembodegem, Belgium), Schaedler agar (BD) or Tryptic Soy Agar (BD) supplemented with 5\% sheep blood. All strains were identified by $16 \mathrm{~S}$ rRNA gene sequencing. Bacteroides fragilis ATCC $25285^{\mathrm{T}}$ was obtained from the CCUG.

\section{() Biomed Central}

(c) 2012 Santiago et al; licensee BioMed Central Ltd. This is an open access article distributed under the terms of the Creative Commons Attribution License (http://creativecommons.org/licenses/by/2.0), which permits unrestricted use, distribution, and reproduction in any medium, provided the original work is properly cited. 
Table 1 Values of MIC and MBC of DQC belonging to 4 species of the genus Atopobium

\begin{tabular}{|c|c|c|c|c|}
\hline Test No. & Species & Strain & MIC $(\mu \mathrm{g} / \mathrm{ml})$ & $\mathrm{MBC}(\mu \mathrm{g} / \mathrm{ml})$ \\
\hline ST1 & Atopobium vaginae & CCUG 44125 & 0.25 & 0.25 \\
\hline $\mathrm{ST} 2$ & Atopobium rimae & CCUG 31168 & 1 & 1 \\
\hline ST3 & Atopobium vaginae & FB101-3 & 0.5 & 0.5 \\
\hline ST4 & Atopobium vaginae & FB106b & $<0.0625$ & $<0.0625$ \\
\hline ST5 & Atopobium vaginae & VMF0914COL43 & $<0.0625$ & $<0.0625$ \\
\hline ST6 & Atopobium vaginae & VMF0914COL13 & $<0.0625$ & $<0.0625$ \\
\hline ST7 & Atopobium vaginae & VMF0907COL23 & $<0.0625$ & $<0.0625$ \\
\hline ST8 & Atopobium vaginae & PB2003/009-T1-4 & $<0.0625$ & $<0.0625$ \\
\hline ST9 & Atopobium vaginae & PB2003/017-T1-2 & $<0.0625$ & $<0.0625$ \\
\hline ST10 & Atopobium vaginae & BVS067 & $<0.0625$ & $<0.0625$ \\
\hline ST11 & Atopobium vaginae & CCUG 44258 & 0.0625 & 0.0625 \\
\hline ST12 & Atopobium vaginae & FB145-BA-14A & $<0.0625$ & $<0.0625$ \\
\hline ST13 & Atopobium vaginae & FB106B & 0.0625 & 0.0625 \\
\hline ST14 & Atopobium vaginae & FB158-CNA-2C & $<0.0625$ & $<0.0625$ \\
\hline ST15 & Atopobium vaginae & FB160-CNAB-7A & $<0.0625$ & $<0.0625$ \\
\hline ST16 & Atopobium vaginae & FB160-CNAB-7 & $<0.0625$ & $<0.0625$ \\
\hline ST17 & Atopobium vaginae & FB130-CNAB-2aD & 0.5 & 0.5 \\
\hline ST18 & Atopobium vaginae & FB010-06 & $<0.0625$ & $<0.0625$ \\
\hline ST19 & Atopobium vaginae & CCUG $38953^{\top}$ & $<0.0625$ & $<0.0625$ \\
\hline ST20 & Atopobium vaginae & FB106C & 0.0625 & 0.0625 \\
\hline ST21 & Atopobium vaginae & FB101-3C & $<0.0625$ & $<0.0625$ \\
\hline ST22 & Atopobium vaginae & BVS068 & 0.5 & 0.5 \\
\hline ST23 & Atopobium parvulum & VMF1313W43 & 2 & 2 \\
\hline ST24 & Atopobium parvulum & VMF1620W23 & 2 & 2 \\
\hline ST25 & Atopobium parvulum & CCUG 32760 & 1 & 1 \\
\hline ST26 & Atopobium minutum & CCUG 31167 & 2 & 2 \\
\hline ST27 & Atopobium vaginae & FB101-2 & $<0.0625$ & $<0.0625$ \\
\hline ST28 & Atopobium vaginae & PB2003/189-T1-4 & $<0.0625$ & $<0.0625$ \\
\hline
\end{tabular}

DQC: dequalinium chloride; MBC: Minimal Bactericidal Concentration; MIC: Minimal Inhibitory Concentration

\section{Broth microdilution assay}

A $10,240 \mu \mathrm{g} / \mathrm{ml}$ stock solution of DQC was prepared by dissolving $102.4 \mathrm{mg}$ DQC (Analysis by Medinova AG, Zurich, Switzerland) in $10 \mathrm{ml} \mathrm{HPLC}$ water. DQC was dissolved by sonication (Labsonic 1510, B. Brauer, Melsungen, Germany) during 5 minutes at $150 \mathrm{~W}$ and incubation in a warm water bath $\left(37^{\circ} \mathrm{C}\right)$ for 2 hours.

A serial dilution series ranging from $512 \mu \mathrm{g} / \mathrm{ml}$ to $0.0625 \mu \mathrm{g} / \mathrm{ml}$ DQC was used and tested in duplicate.

Brucella Broth (BD), supplemented with vitamin K (1 $\mu \mathrm{g} / \mathrm{ml})$, hemin $(5 \mu \mathrm{g} / \mathrm{ml})$ and laked horse blood (5\%) was prepared [10]. The different Atopobium spp. and strains were plated onto Colombia agar (BD) and cultured for 72 hours in an anaerobic chamber (BugBox, LedTechno, Heusden-Zolder, Belgium) at $37^{\circ} \mathrm{C}$. The Brucella Broth was pre-reduced, prior to use, for 2 hours in the anaerobic chamber at $37^{\circ} \mathrm{C}$. Every cultured strain was suspended in physiological water until a 1 McFarland density $\left(3 \times 10^{8} \mathrm{cfu} / \mathrm{ml}\right)$ was obtained, $1 \mathrm{ml}$ of this suspension was centrifuged for 5 minutes at 7,000 $\mathrm{g}$, and $900 \mu \mathrm{l}$ of the supernatans was removed. In the anaerobic chamber, at $37^{\circ} \mathrm{C}$, the $100 \mu \mathrm{l}$ of remaining bacterial suspension was added to $5 \mathrm{ml}$ pre-reduced Brucella Broth, yielding a final load of $6 \times 10^{6} \mathrm{cfu} / \mathrm{ml}$, and homogenized.

For each six strains, two 96-well microtiterplates (Axygen, San Francisco, Ca) were used. Plate 1.1 contained concentrations of $512 \mu \mathrm{g} / \mathrm{ml}$ to $8 \mu \mathrm{g} / \mathrm{ml}$ of DQC in rows A to $\mathrm{G}$ and no antibiotic in row $\mathrm{H}$. Plate 1.2 contained $4 \mu \mathrm{g} / \mathrm{ml}$ to $0.0625 \mu \mathrm{g} / \mathrm{ml}$ in rows $A$ to $\mathrm{G}$ and no antibiotic in row H. Per strain, two columns of the two 96-well plates were filled with $100 \mu \mathrm{l}$ of the bacterial suspension in Brucella broth per well.

The inoculated plates were incubated anaerobically at $37^{\circ} \mathrm{C}$ and read after 48 and after 72 hours.

The MIC endpoint was defined as the lowest concentration of DQC that inhibited visible growth of the test 


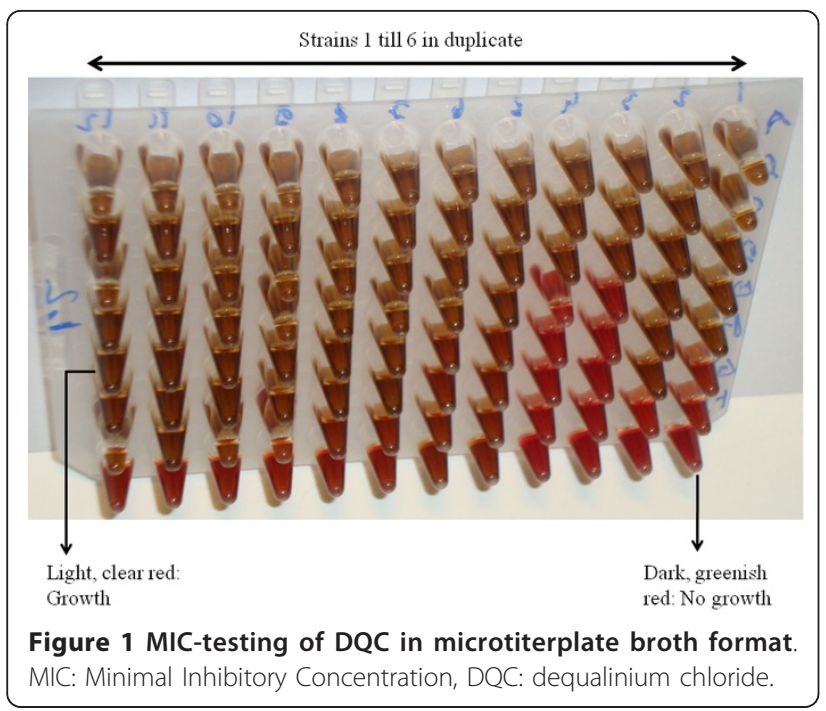

isolate. Brownish, dark red wells were considered as wells without growth and clear and light red wells were considered as wells with growth (Figure 1).

For plates 1.1 and 1.2, a volume of $25 \mu \mathrm{l}$ of each well was plated onto a Colombia agar plate (i.e. solid medium without $\mathrm{DQC}$ ) to confirm the presence or absence of growth and to determine the MBC. These culture plates were incubated for 72 hours in the anaerobic chamber at $37^{\circ} \mathrm{C}$.

In addition, the MICs of $A$. vaginae CCUG 44258, CCUG 44125 and CCUG $38953^{\mathrm{T}}$ and B. fragilis ATCC $25285^{\mathrm{T}}$ were tested for clindamycin and metronidazole using the broth microdilution assay under the same conditions, to validate the MIC determination approach used here.

\section{Results}

The MIC- and MBC-values of the 28 Atopobium strains for DQC are shown in Table 1. The MIC and MBC range of DQC was determined as $<0.0625-2 \mu \mathrm{g} / \mathrm{ml}$ with an MIC90-value of $2 \mu \mathrm{g} / \mathrm{ml}$.
All wells that were determined to contain bacterial growth (based on a light, clear red colour of the growth medium in the well), and that were cultured on solid medium without DQC, showed growth on the solid medium. All wells for which no growth could be observed (based on a dark, brownish red colour of the growth medium in the well) and that had been cultured on solid medium without DQC, showed no growth on solid medium. This indicates that the MIC values are similar to the MBC values, i.e. not only growth was inhibited at the MIC-values, as determined by growth in microtiterplate broth, but also cells were killed, as no growth could be obtained when culturing $25 \mu$ of the broth from the wells were no growth was observed, on solid media without DQC.

The MICs of $A$. vaginae CCUG 44258, 44125 and $38953^{\mathrm{T}}$ for clindamycin and metronidazole were comparable to those reported in other studies $[8,15]$ (Table 2). The MIC of B. fragilis ATCC $25285^{\mathrm{T}}$ for metronidazole was similar to that reported previously [15] (Table 2).

\section{Discussion}

Petersen et al. (2002) assessed the therapeutic efficacy of $10 \mathrm{mg}$ DQC in a study population of 121 patients with various vaginal infections (bacterial vaginosis, fluor vaginalis, vulvo-vaginal candidiasis, trichomoniasis), by monitoring the clinical symptoms, the vaginal $\mathrm{pH}$ and the number of lactobacilli. A positive effect on the restoration of the vaginal ecosystem and good tolerability was observed, with a limited number of adverse events (5.8\%) [13]. In a recent multicentre study (15 centres in 5 countries), comprising 321 women with BV, randomized to receive either DQC $(\mathrm{n}=164)$ or vaginal clindamycin cream $(\mathrm{n}=157)$, Weissenbacher et al. [14] found vaginal DQC tablets to be equally effective as vaginal clindamycin cream and to be well tolerated with no systemic safety concerns.

Together with the broad antibacterial activity of DQC against various $\mathrm{BV}$-associated microorganisms, i.e.

Table 2 Comparison of Atopobium vaginaeisolates and Bacteroides fragilistype strain MIC-values ( $\mu \mathrm{g} / \mathrm{ml})$ for clindamycin and metronidazole

\begin{tabular}{|c|c|c|c|c|}
\hline & Atopobium vaginae CCUG 44258 & Atopobium vaginae CCUG 44125 & $\begin{array}{l}\text { Atopobium vaginae } \\
\text { CCUG } 38953^{\mathrm{T}}\end{array}$ & $\begin{array}{l}\text { Bacteroides fragilis } \\
\text { ATCC } 25285^{\top}\end{array}$ \\
\hline Metronidazole [this study] ${ }^{a}$ & 32 & 128 & 32 & 1 \\
\hline Metronidazole $[15]^{b}$ & 4 & 8 & 16 & 1 \\
\hline Metronidazole $[10]^{a}$ & NT & NT & $>32$ & NT \\
\hline Clindamycin [this study] ${ }^{a}$ & $<0.0625$ & $<0.0625$ & $<0.0625$ & $<0.0625$ \\
\hline Clindamycin $[8]^{c}$ & $<0.016$ & $<0.016$ & $<0.016$ & NT \\
\hline Clindamycin $[16]^{a}, *$ & NT & NT & NT & $\leq 0.25->16$ \\
\hline
\end{tabular}

MIC: Minimal Inhibitory Concentration; NT: Not tested

a: CLSI broth microdilution, b: Agar dilution method, c: E-test

* Range based on the MICs of 232 clinical isolates of $B$. fragilis (the type strain was not included) 
Gardnerella vaginalis, Bacteroides spp. and Prevotella spp., as shown in previous studies [11,12], our findings for $A$. vaginae $\mathrm{DQC}$ susceptibility add to the value of DQC as an alternative treatment for BV and vaginal infections.

The color change of the broth, which we observed when bacterial growth was absent and which was useful to determine the MIC-value, has not been previously mentioned in other publications using the same method. Possibly, it can be explained by the effect of living respectively dead bacteria on the laked horse blood in the broth.

\section{Conclusions}

We conclude that DQC inhibits and kills clinical isolates of $A$. vaginae at concentrations similar to clindamycin and lower than metronidazole $[8,15]$.

\section{Acknowledgements}

Guido Lopes dos Santos Santiago is indebted for a PhD Research funded by a research grant of the Concerted Research Actions of the University of Ghent. The study was sponsored by Medinova AG (Zurich, Switzerland).

\section{Author details}

${ }^{1}$ Laboratory Bacteriology Research, Faculty Medicine \& Health Sciences, University of Ghent, De Pintelaan 185, Ghent 9000, Belgium. ${ }^{2}$ Medinova AG, Eggbuehlstrasse 14, Zurich 8052, Switzerland. ${ }^{3}$ Department of Obstetrics and Gynaecology, Faculty of Medicine and Health Sciences, Ghent University, De Pintelaan 185, Ghent, Belgium.

\section{Authors' contributions}

MV and GL participated in the development of the study design and in the analysis and interpretation of the data. MV, HV, PG, FW and GL participated in the writing of the report. All authors read and approved the final manuscript.

\section{Competing interests}

The authors declare that they have no competing interests.

Received: 7 October 2011 Accepted: 19 March 2012

Published: 19 March 2012

\section{References}

1. Hillier SL, Holmes KK, Marrazzo JM: Bacterial vaginosis. In Sexually transmitted diseases.. 4 edition. Edited by: Holmes KK. New York: McGrawHill; 2008:737-68.

2. Verhelst $R$, Verstraelen $H$, Claeys $G$, Verschraegen $G$, Delanghe J, Van Simaey L, De Ganck C, Temmerman M, Vaneechoutte M: Cloning of 165 rRNA genes amplified from normal and disturbed vaginal microflora suggests a strong association between Atopobium vaginae, Gardnerella vaginalis and bacterial vaginosis. BMC Microbiol 2004, 4:16.

3. Verstraelen $H$, Verhelst $\mathrm{R}$ : Bacterial vaginosis: an update on diagnosis and treatment. Expert Rev Anti Infect Ther 2009, 7:1109-1124.

4. Workowski KA, Berman SM: Sexually transmitted diseases treatment guidelines, 2006. MMWR Recomm Rep 2006, 55(RR-11):1-94.

5. Bradshaw CS, Morton AN, Hocking J, Garland SM, Morris MB, Moss LM Horvath LB, Kuzevska I, Fairley CK: High recurrence rates of bacterial vaginosis over the course of 12 months after oral metronidazole therapy and factors associated with recurrence. J Infect Dis 2006, 193:1478-1486.

6. Larsson PG, Forsum U: Bacterial vaginosis-a disturbed bacterial flora and treatment enigma. APMIS 2005, 113:305-316.

7. Beigi RH, Austin MN, Meyn LA, Krohn MA, Hillier SL: Antimicrobial resistance associated with the treatment of bacterial vaginosis. Am J Obstet Gynecol 2004, 191(4):1124-1129.
8. De Backer E, Verhelst $R$, Verstraelen H, Claeys $G$, Verschraegen $G$, Temmerman M, Vaneechoutte M: Antibiotic susceptibility of Atopobium vaginae. BMC Infect Dis 2006, 6:51.

9. Bradshaw CS, Tabrizi SN, Fairley CK, Morton AN, Rudland E, Garland SM: The association of Atopobium vaginae and Gardnerella vaginalis with bacterial vaginosis and recurrence after oral metronidazole therapy. $J$ Infect Dis 2006, 194:828-836.

10. Ferris MJ, Masztal A, Aldridge KE, Fortenberry JD, Fidel PL Jr, Martin DH: Association of Atopobium vaginae, a recently described metronidazole resistant anaerobe, with bacterial vaginosis. BMC Infect Dis 2004, 4:5.

11. Della Casa V, Noll H, Gonser S, Grob P, Graf F, Pohlig G: Antimicrobial activity of dequalinium chloride against leading germs of vaginal infections. Arzneimittelforschung 2002, 52:699-705.

12. Strecker M, Kokemohr H, Teucher T, Schmitz H: Antiseptika gegen vulvovaginitiden. TW Gynäkologie 1993, 6:409-412.

13. Petersen EE, Weissenbacher ER, Hengst P, Spitzbart H, Weise W, Wolff F, Dreher E, Ernst U, Della Casa V, Pohlig G, Graf F, Kaiser RR: Local treatment of vaginal infections of varying etiology with dequalinium chloride or povidone iodine. A randomised, double-blind, active-controlled, multicentric clinical study. Arzneimittelforschung 2002, 52:706-715.

14. Weissenbacher ER, Donders G, Unzeitig V, Martinez de Tejada B, Gerber S, Halaška M, Špaček J, Fluomizin Study Group: A comparison of dequalinium chloride vaginal tablets (fluomizin) and clindamycin vaginal cream in treatment of bacterial vaginosis: single blind, randomized clinical trial of efficacy and safety. Gynecol Obstet Invest

15. De Backer E, Dubreuil L, Brauman M, Acar J, Vaneechoutte M: In vitro activity of secnidazole against Atopobium vaginae, an anaerobic pathogen involved in bacterial vaginosis. Clin Microbiol Infect 2010, 16:470-472

16. Karlowsky JA, Walkty AJ, Adam HJ, Baxter MR, Hoban DJ, Zhanel GG Prevalence of Antimicrobial Resistance among Clinical Isolates of Bacteroides fragilis group in Canada in 2010-2011: CANWARD Surveillance Study. Antimicrob Agents Chemother.

doi:10.1186/1756-0500-5-151

Cite this article as: Lopes dos Santos Santiago et al:: Susceptibility testing of Atopobium vaginae for dequalinium chloride. BMC Research Notes 2012 5:151.

\section{Submit your next manuscript to BioMed Central and take full advantage of:}

- Convenient online submission

- Thorough peer review

- No space constraints or color figure charges

- Immediate publication on acceptance

- Inclusion in PubMed, CAS, Scopus and Google Scholar

- Research which is freely available for redistribution 